\title{
Flexural Behavior of Beams Reinforced with Steel Bars Exceeding the Nominal Yield Strength
}

\section{Abstract}

If steel manufactures usually comply with the minimum code specifications, the nominal yield strength of rebar can however be significantly exceeded in many countries, depending on the steel manufacturing processes. Such an increase in yield strength can have negative effects on the flexural behavior of beams designed as tension controlled, and reduce their ductility, an essential property in seismic resisting structures. An experimental and analytical study of the flexural behavior of reinforced concrete (RC) beams was conducted through the investigation of the Moment-Curvature relationships and the ultimate steel strains. The main variable was the level of the actual steel yield stress as compared to the nominal value. It was found that unexpectedly high values of steel yield stress reduce the beam ductility and violate the tension-control condition which was enforced in the design stage. Appropriate design corrections are proposed to account for high yield stress values in order to achieve the desired ductility of beams while maintaining the moment capacities.

\section{Keywords}

Reinforced concrete, beam flexure, ductility, moment curvature, yield strength
Abdelhamid Charif ${ }^{\text {a }}$

Shehab M. Mourad ${ }^{\text {b }}$

M. Iqbal Khan ${ }^{\mathrm{c}}$

${ }^{a}$ King Saud University, acharif@ksu.edu.sa

${ }^{\mathrm{b}}$ King Saud University, smourad@ksu.edu.sa

${ }^{\mathrm{c}}$ King Saud University, miqbal@ksu.edu.sa

http://dx.doi.org/10.1590/1679-78251683

Received 07.11.2014

In revised form 22.01.2016

Accepted 12.02.2016

Available online 17.02.2016

\section{INTRODUCTION}

While much attention has been given to the effect of the variability of concrete strength and properties on the response of reinforced concrete structures, there is little, if any, information on the effects of variability of steel strength. This lack of interest may be explained by the assumed assurance that steel manufactures are always complying with minimum code specifications. However, steel mechanical properties are sometimes exceeding the minimum nominal strength values for a specific grade of steel. This happens in many countries as there are different steel producers who adopt different methods of manufacturing. The mechanical properties of steel are governed by the 
production technique, chemical compositions, mechanical working of rebar, and the method of heat treatment as described by Davis et al. (1982). Seismic standards have been developed with the aim of allowing steel to yield without rupture during an earthquake, in order to enhance seismic energy absorption of the structure and avoid collapse. For this purpose, steel bars should possess high strength with sufficient ductility and low variation in yield strength to experience large number of inelastic cycles of deformation with large plastic strains. In this regard, most international specifications outline and control the mechanical properties requirements for rebar to be used in seismic resistant systems as reported by Milbourn (2010), and shown in Table 1.

\begin{tabular}{|c|c|c|c|c|c|}
\hline \multirow{2}{*}{ Rebar Specifications } & \multirow{2}{*}{$\begin{array}{l}\text { Steel } \\
\text { Grade }\end{array}$} & \multicolumn{3}{|c|}{$\begin{array}{c}\text { Strength requirements } \\
\text { Ratio = Actual/Nominal }\end{array}$} & \multirow{2}{*}{$\begin{array}{c}\begin{array}{c}\text { Ductility } \\
\text { requirements }\end{array} \\
\text { Elongation }(\%)\end{array}$} \\
\hline & & $\begin{array}{l}f_{y \text { nominal }} \\
(\mathrm{MPa})\end{array}$ & $f_{y}$ ratio & $f_{u}$ ratio & \\
\hline \multirow{2}{*}{$\begin{array}{c}\text { Chinese Standard GB } \\
1449.2: 2007\end{array}$} & HRB400E & 400 & $\leq 1.3$ & $\geq 1.25$ & $\geq 16$ \\
\hline & HRB500E & 500 & $\leq 1.3$ & $\geq 1.25$ & $\geq 15$ \\
\hline \multirow{2}{*}{$\begin{array}{c}\text { Australian/New Zealand } \\
\text { Standard AS/NZS } \\
4671: 2001\end{array}$} & $300 \mathrm{E}$ & 300 & $\leq 1.27$ & $\geq 1.15, \leq 1.5$ & $\geq 15$ \\
\hline & $500 \mathrm{E}$ & 500 & $\leq 1.20$ & $\geq 1.15, \leq 1.4$ & $\geq 10$ \\
\hline \multirow{2}{*}{$\begin{array}{c}\text { British Standard BS } \\
\text { 4449:2005 }\end{array}$} & B500B & 500 & $\leq 1.30$ & $\geq 1.08$ & $\geq 5$ \\
\hline & B500C & 500 & $\leq 1.30$ & $\geq 1.15, \leq 1.35$ & $\geq 7.5$ \\
\hline \multirow{2}{*}{$\begin{array}{c}\text { American Standard } \\
\text { ASTM A706 - ASTM } \\
\text { A615- 09b }\end{array}$} & Grade 60 & 420 & $\leq 1.29$ & $\geq 1.25$ & $\begin{array}{l}\geq 14: \phi=10-19 \mathrm{~mm} \\
\geq 12: \phi=22-36 \mathrm{~mm}\end{array}$ \\
\hline & Grade 80 & 550 & $\leq 1.23$ & $\geq 1.25$ & $\geq 12: \phi=10-36 \mathrm{~mm}$ \\
\hline
\end{tabular}

Table 1: Mechanical properties requirements for seismic resistant rebars.

The increase in both yield and ultimate strengths of rebars will certainly improve the member's strength but however it may also affect adversely the member's ductility. This is particularly important for beams which are usually designed as tension controlled members, where at the ultimate state, tension steel should exceed the yield limit and reach a minimum strain of 0.005 as specified by ACI-318R-11 (2011). For such beams, steel bars will sufficiently yield before concrete reaches its compressive crushing strength allowing significant increase in deflections, and showing enough warning before failure. For such reasons, beams with a minimum tensile steel strain of 0.005 are considered to be fully ductile. An unsuspected increase in yield strength may therefore change the tension control of a beam and violate the minimum 0.005 strain condition.

Al-Haddad (1995, 2006) studied the effect of high yield strength of Saudi rebar on the curvature ductility factor. It was concluded that the ACI-318 provisions of limiting maximum longitudinal steel ratio do not ensure sufficient ductility for conventional and seismic designs. Youcef and Chemrouk (2012) also reported ductility reduction with higher steel ratios and yield limits. Appropriate compression steel to retrieve the desired ductility was recommended. Zhou et al. (2011) studied the 
effects of steel ratio and yield level on both deformability and strength of RC beams, and made appropriate recommendations in order to achieve the desired level of ductility without adversely affecting the strength by combining compression and transverse steel.

In the Middle East and Gulf Region, there are at least six producers of deformed rebars, all complying with ASTM A 615M specifications. Steel is manufactured using either tempered or quenched processes to produce bars with minimum yield strength of $420 \mathrm{MPa}$, and minimum ultimate strength $620 \mathrm{MPa}$. However, large differences in yield strength values are noticed among producers using different manufacturing processes, leading to substantially different mean-to-nominal yield strength ratios. There is consequently a substantial risk that a beam initially designed to fail in a ductile mode may fail in a brittle manner. It is therefore necessary to investigate the effect of the increase in rebar yield strength on beam ductility.

The objective of the present study is to investigate the effect of local manufactured steel on the flexural behavior of beams in terms of ductility and moment capacity. The investigation is performed experimentally and verified analytically. In addition, a parametric study is conducted to demonstrate the effect of high yield strength of rebars on the ductility and bending capacity of beams for different steel ratios and beam sections.

\section{EXPERIMENTAL INVESTIGATION}

\subsection{Variation of Steel Strength}

In the first part of the experimental investigation, random samples were taken from two different local steel producers "A" and "B" that are confirming to ASTM A 615M grade 60, but with unspecified manufacturing processes. The nominal yield and ultimate strengths are $420 \mathrm{MPa}$ and $620 \mathrm{MPa}$ respectively. Three specimens were tested for each bar diameter, the yield and and ultimate strengths were recorded as well as the mean values and coefficient of variation. The ratio of mean yield strength to nominal yield value $\left(\gamma_{\mathrm{y}}\right)$ and the ratio of mean ultimate strength to nominal ultimate value $\left(\gamma_{\mathrm{u}}\right)$ were computed for each rebar diameter, and the results are shown in Table 2 for both producers "A" and "B". In fact both yield and ultimate strengths vary considerably from small to large diameters even for the same steel producer. For producer "A", the ratio of mean yield stress to nominal value varies from 1.26 to 1.39 , while the ultimate ratio ranges is from 1.16 to 1.26 . For producer "B", the range variation is 1.30 to 1.46 in yield stress and 1.06 to 1.13 in ultimate strength.

As the steel tensile strength depends on the manufacturing process, an investigation was made to compare the tensile strength of grade 60 rebars produced by two different processes; tempering and quenching techniques. The nominal yield and nominal ultimate strengths are again 420 and 620 MPa respectively. Tensile tests were performed with different rebar diameters for each steel manufacturing type. The ratios, mean to nominal, for yield strength " $\gamma_{\mathrm{y}}$ " and the ratio of mean to nominal ultimate strength " $\gamma_{\mathrm{u}}$ " were computed and given in Table 3 for different rebar diameters. As can be noticed, the values of $\gamma_{\mathrm{y}}$ for rebars prepared by the tempering process are very close to 1.00, while the values of $\gamma_{\mathrm{y}}$ for rebars prepared by quenching process are much higher and can reach up to 1.43. However the values of $\gamma_{u}$ for both types of steel rebars are within reasonable range (1.00 to 1.15). These results indicate that rebars produced by the quenching process exhibit high values of yield strength as compared to the nominal value. Typical stress-strain curves for 16-mm and 20-mm 
rebars manufactured by both tempering and quenching processes are shown in Figures 1a and 1b respectively. There is a significant variation in yield strength whereas the ultimate strengths are quite close. The quenched process delivered a yield stress much higher than the nominal value. In addition, the rebars develop a yield plateau until a strain less than or equal to 0.02, which is then followed by nonlinear hardening until the ultimate strength is reached at about 0.10 strain. It is anticipated that such high values of yield strength, will have a significant effect on the flexural behavior of beams.

\begin{tabular}{ccccccccc}
\hline \hline & \multicolumn{3}{c}{ Producer "A" } & \multicolumn{3}{c}{ Producer "B" } \\
\hline \multicolumn{1}{c}{ Yield } & \multicolumn{2}{c}{$\begin{array}{c}\text { Ultimate } \\
\text { Strength }\end{array}$} & \multicolumn{2}{c}{$\begin{array}{c}\text { Yield } \\
\text { Strength }\end{array}$} & $\begin{array}{c}\text { Ultimate } \\
\text { Strength }\end{array}$ \\
\hline $\begin{array}{c}\text { Bar } \\
\text { (mm })\end{array}$ & $\gamma_{y}$ & C.O.V & $\gamma_{u}$ & C.O.V & $\gamma_{y}$ & C.O.V & $\gamma_{u}$ & C.O.V \\
\hline 8 & 1.28 & $1.4 \%$ & 1.16 & $1.2 \%$ & -- & -- & -- & -- \\
10 & 1.28 & $2.1 \%$ & 1.23 & $1.9 \%$ & 1.40 & $1.3 \%$ & 1.08 & $1.8 \%$ \\
12 & 1.39 & $0.6 \%$ & 1.26 & $2.7 \%$ & 1.38 & $3.48 \%$ & 1.07 & $0.91 \%$ \\
14 & 1.31 & $1.7 \%$ & 1.24 & $0.7 \%$ & 1.30 & $3.98 \%$ & 1.06 & $1.26 \%$ \\
16 & 1.26 & $3.0 \%$ & 1.23 & $2.0 \%$ & 1.46 & $3.40 \%$ & 1.13 & $1.89 \%$ \\
18 & 1.32 & $3.4 \%$ & 1.24 & $0.6 \%$ & 1.39 & $2.50 \%$ & 1.11 & $3.49 \%$ \\
20 & 1.27 & $3.3 \%$ & 1.24 & $1.6 \%$ & 1.35 & $3.52 \%$ & 1.08 & $2.38 \%$ \\
25 & 1.27 & $2.3 \%$ & 1.21 & $1.0 \%$ & 1.37 & $5.79 \%$ & 1.13 & $0.46 \%$ \\
32 & -- & -- & -- & -- & 1.31 & $2.88 \%$ & 1.07 & $3.69 \%$ \\
Mean & 1.30 & & 1.23 & & 1.37 & & 1.09 & \\
\hline \hline
\end{tabular}

Table 2: Variation of yield and ultimate strengths of different rebars from different local producers.

\begin{tabular}{ccccc}
\hline \hline \multirow{2}{*}{$\begin{array}{c}\text { Bar } \Phi \\
(\mathrm{mm})\end{array}$} & \multicolumn{2}{c}{$\begin{array}{c}\text { Tempered steel re- } \\
\text { bars }\end{array}$} & \multicolumn{2}{c}{$\begin{array}{c}\text { Quenched steel re- } \\
\text { bars }\end{array}$} \\
\cline { 2 - 5 } & $\gamma_{y}$ & $\gamma_{u}$ & $\gamma_{y}$ & $\gamma_{u}$ \\
\hline 10 & 1.00 & 1.06 & 1.40 & 0.97 \\
16 & 1.01 & 1.10 & 1.43 & 1.15 \\
18 & 1.00 & 1.07 & 1.31 & 1.11 \\
20 & 0.99 & 1.09 & 1.30 & 1.11 \\
\hline \hline
\end{tabular}

Table 3: Comparison of mean-to-nominal strength values for tempered and quenched steel rebars. 


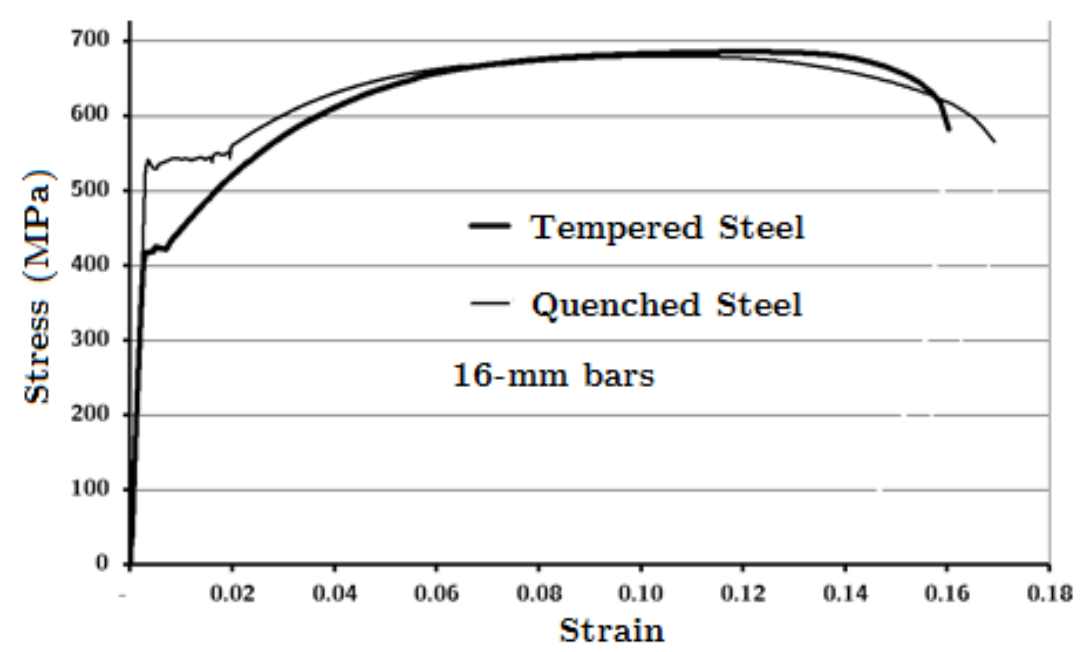

Figure 1a: Typical stress-strain curves for 16-mm rebars.

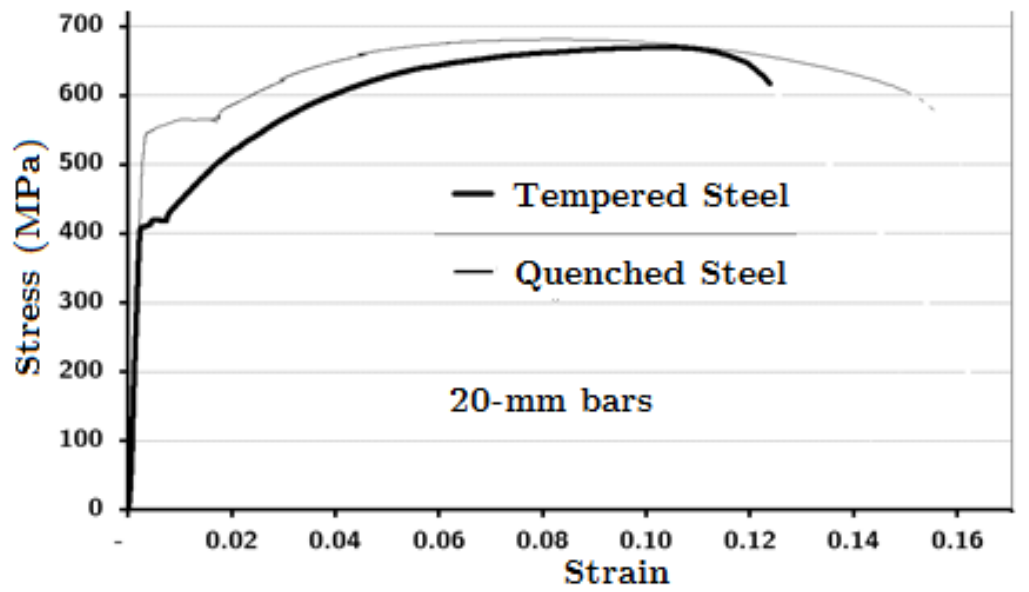

Figure 1b: Typical stress-strain curves for 20-mm rebars.

\subsection{Flexural Behavior of Beam Specimens}

The experimental investigation on beam specimens was part of undergraduate-senior student project at King Saud University by Allorani et al. (2012). A total of 4 beams were tested. The first group with two specimens used tempered steel rebars and is designated as "T", whereas in the second group "Q" of beams, quenched steel rebars were used. Grade 60 steel was used in both groups with nominal yield stress of $420 \mathrm{MPa}$ and nominal ultimate strength of $620 \mathrm{MPa}$. The concrete used had a compressive strength of $25 \mathrm{MPa}$. Two specimens of each group were designed for two different tension steel strains (0.004 and 0.0065) at concrete crushing. The beam specimens of the first group were designated as T-0.004 and T-0.0065, whereas specimens of the second group were identified as Q-0.004 and Q-0.0065 respectively. Details of beam specimens are shown in Figure 2. All beams were $3.1 \mathrm{~m}$ long with a section of $200 \times 500 \mathrm{~mm}$. Top and bottom covers were adjusted in order to achieve the desired effective depth that corresponds to the design failure strains in bottom 
steel. The flexural reinforcement was provided in two layers. One 8-mm bar was used in compression side to fix the stirrups. Shear reinforcement of all beams was designed according to ACI-318R11 in order to avoid shear failure. The effective depth corresponding to each failure steel strain was computed based on the assumption that the ultimate compressive strain in concrete is 0.003 , and the nominal yield stress of both groups is $420 \mathrm{MPa}$. The computed effective depths corresponding to groups "T" and "Q" were $425.9 \mathrm{~mm}$ and $444.0 \mathrm{~mm}$ respectively.

The specimens were instrumented to provide strain measurements; two strain gauges were installed on tension steel and compression steel of beam specimens at mid span. The strain gauges in the tension steel were placed in the bottom layer of the flexural reinforcement. One linear voltage differential transducer (LVDT) with $50 \mathrm{~mm}$ travel was used to measure mid span deflections. The load was monitored using load cells at third points. The beams were simply supported and two equal concentrated loads were applied at third point of the span, as shown in Figure 3. The load was applied by $10000 \mathrm{kN}$ upgraded Amsler press with an electronic control using a $2000 \mathrm{kN}$ measuring range option. Load was applied continuously at a displacement rate of $2 \mathrm{~mm}$ per minute up to failure. Load, deflections and strains were recorded using a data acquisition system.
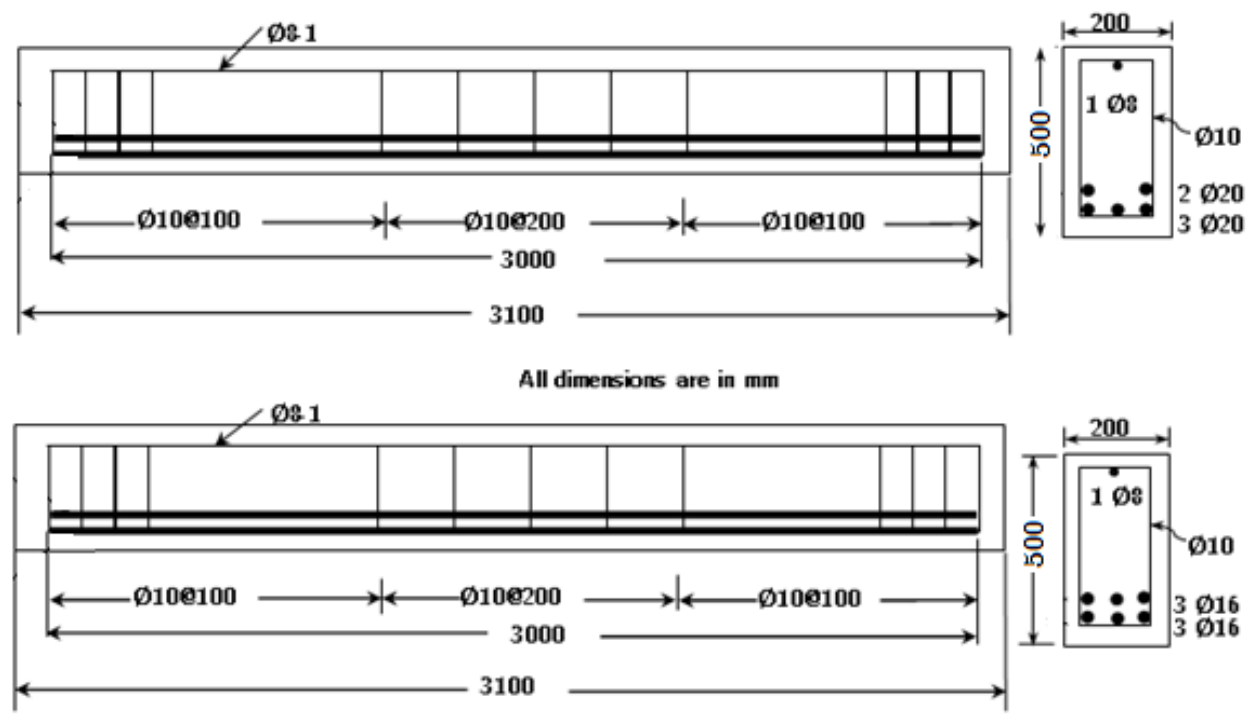

Figure 2: Details of beam specimens.

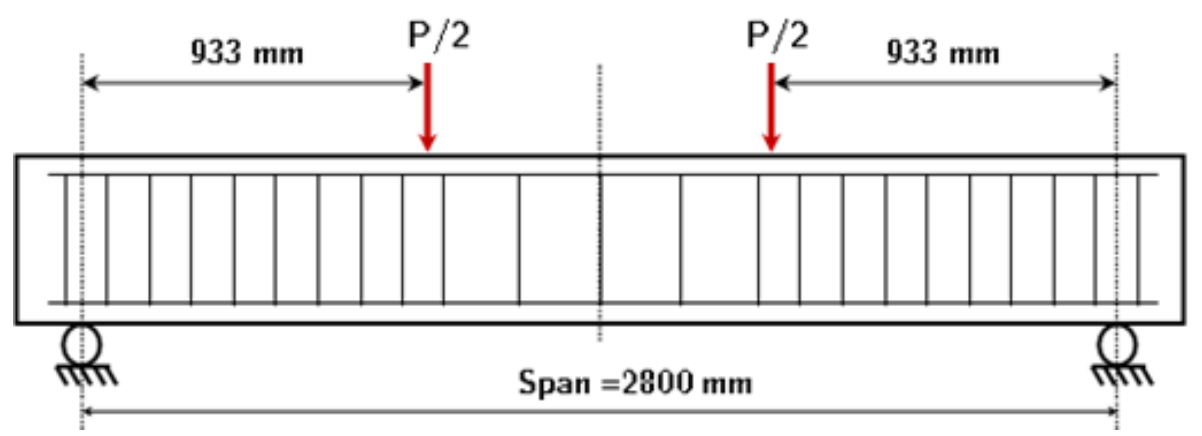

Figure 3: Details of loading arrangement. 
The measured moment-curvature relationships of the four specimens are shown in Figure 4. The values of ultimate moments, curvatures and ductility are given in Table 4 . It is noticed that specimens T-0.0065 and Q-0.0065 exhibit higher curvature and ductility as compared to specimens T0.004 and Q-0.004, because of their lower steel reinforcement. However, specimens made of quenched rebars; Q-0.004 and Q-0.0065, exhibit higher ultimate moments with less curvature and ductility as compared to those specimens made of tempered steel, T-0.004 and T-0.0065. Such behavior was expected since "Q" rebars have higher yield strength resulting in reduction of the steel strain at failure.

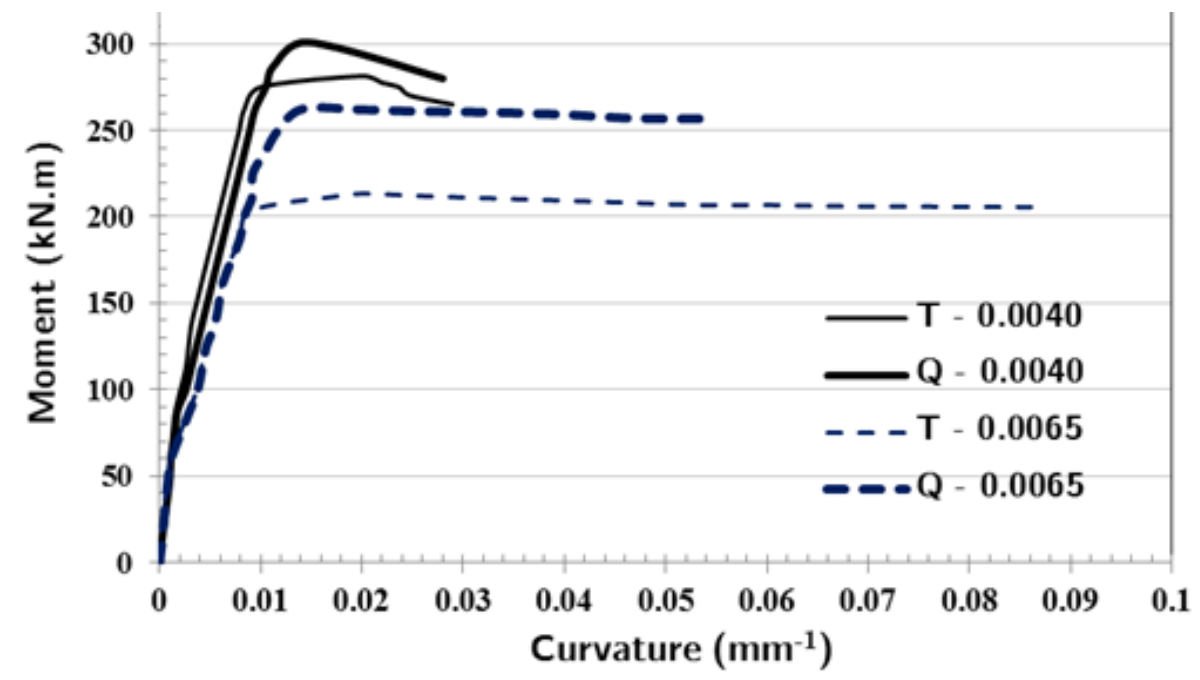

Figure 4: Moment-curvature relationship of the tested beam specimens.

\begin{tabular}{ccccc}
\hline \hline Specimen & $\begin{array}{c}\text { Ultimate } \\
\text { moment }(\mathrm{kN} . \mathrm{m})\end{array}$ & $\begin{array}{c}\text { Curvature at first } \\
\text { yield } \\
\phi_{y}\left(\mathrm{~mm}^{-1}\right)\end{array}$ & $\begin{array}{c}\text { Ultimate } \\
\text { curvature } \phi_{u} \\
\left(\mathrm{~mm}^{-1}\right)\end{array}$ & $\begin{array}{c}\text { Curvature ductility } \\
\mu_{\phi}=\phi_{u} / \phi_{y}\end{array}$ \\
\hline T-0.004 & 281.4 & 0.009795 & 0.02895 & 2.96 \\
T-0.065 & 213.15 & 0.009600 & 0.08670 & 9.03 \\
Q-0.004 & 301.1 & 0.009979 & 0.02834 & 2.84 \\
Q-0.065 & 262.5 & 0.008761 & 0.05330 & 6.08 \\
\hline \hline
\end{tabular}

Table 4: Experimental results of beams reinforced with Tempered and Quenched steel.

\section{ANALYTICAL MOMENT-CURVATURE RELATIONSHIP}

The moment-curvature relationships of previous specimens were evaluated analytically using a powerful method of analytical integration of stress resultants across any section. The normal stress resultants for a beam-column member, subjected to an axial force and biaxial bending, are given by: 


$$
\begin{aligned}
& N=\int \sigma d A=\iint \sigma d y d z \\
& M_{y}=\int \sigma z d A=\iint \sigma z d y d z \\
& M_{z}=-\int \sigma y d A=-\iint \sigma y d y d z
\end{aligned}
$$

$N$ is the axial force, $M_{y}$ and $M_{z}$ are bending moments about Y-axis and Z-axis respectively.

Integration of stress resultants (1) over arbitrary shaped sections may be performed numerically or analytically. There are many methods of numerical integration computing area integrals (1) such as those described by Sfakianakis (2009), Bonet et al. (2006), Batistuta et al. (2007), and Charalampakis et al. (2008). Area integrals can be transformed to border integrals using Green's theorem with appropriate numerical techniques as reported by Fafitis (2001), Zupan and Saje (2005), and Charif et al. (2014). Analytical integration is only possible with some particular models and with any polynomial form. This efficient method is used here and is described in details by Charif et al. (2014). Integral relations (1) can be expressed with respect to neutral axis coordinates $(\zeta, \eta)$, as shown in Figure 5. The normal strain depends on the coordinate $\eta$ only:

$$
\varepsilon=\varepsilon_{0}+\kappa \eta
$$

$\varepsilon_{0}$ and $\kappa$ are the centroid normal strain and curvature respectively. Integrals (1) become:

$$
\begin{aligned}
& N=\frac{1}{\kappa} \iint \sigma(\varepsilon) d \zeta d \varepsilon \\
& M_{y}=\frac{1}{\kappa} \iint\left(\zeta \sin \varphi+\frac{\varepsilon-\varepsilon_{0}}{\kappa} \cos \varphi\right) \sigma(\varepsilon) d \zeta d \varepsilon \\
& M_{z}=-\frac{1}{\kappa} \iint\left(\zeta \cos \varphi-\frac{\varepsilon-\varepsilon_{0}}{\kappa} \sin \varphi\right) \sigma(\varepsilon) d \zeta d \varepsilon
\end{aligned}
$$
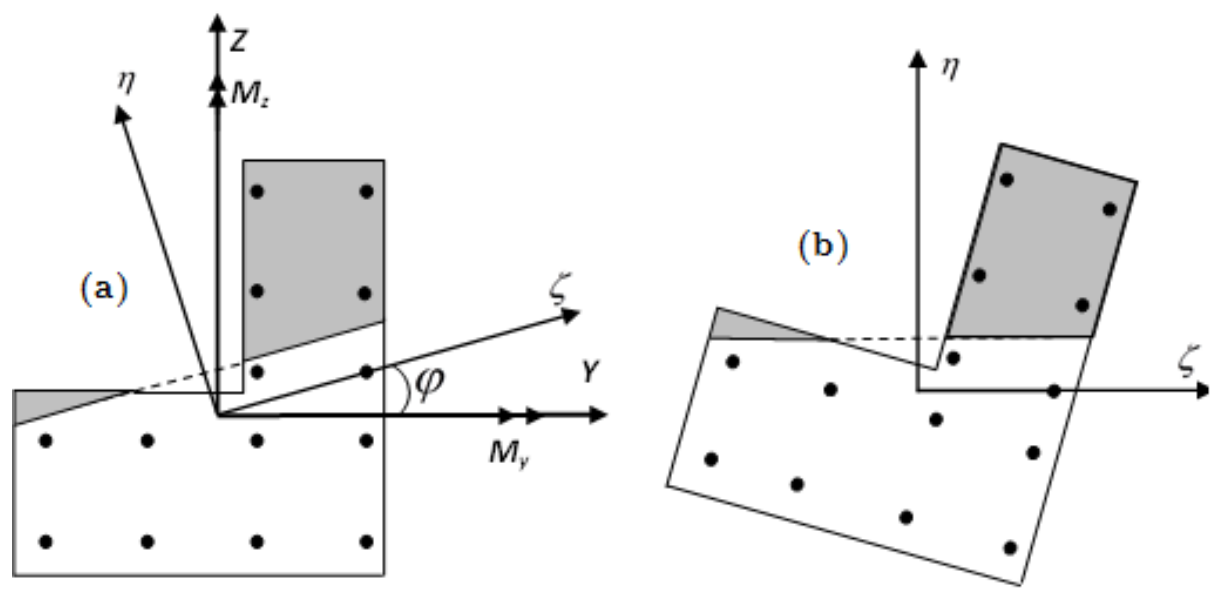

Figure 5: General section under axial force and biaxial bending

(a): Inclined neutral axis in global axes

(b): Rotated section and use of local neutral axes. 
Applying Green transformations to equations (3) leads to:

$$
\begin{aligned}
& N=\frac{1}{\kappa} \oint_{\partial A} \zeta \sigma(\varepsilon) d \varepsilon \\
& M_{y}=\frac{1}{\kappa} \oint_{\partial A}\left(\frac{\zeta^{2}}{2} \sin \varphi+\zeta \frac{\varepsilon-\varepsilon_{0}}{\kappa} \cos \varphi\right) \sigma(\varepsilon) d \varepsilon \\
& M_{z}=-\frac{1}{\kappa} \oint_{\partial A}\left(\frac{\zeta^{2}}{2} \cos \varphi-\zeta \frac{\varepsilon-\varepsilon_{0}}{\kappa} \sin \varphi\right) \sigma(\varepsilon) d \varepsilon
\end{aligned}
$$

Integrals (4) may be determined analytically for some concrete models and in particular for all polynomials as detailed by Charif et al. (2014). A computer program implementing the previous method was developed and used to deliver the moment-curvature relationships.

\section{VERIFICATION OF THE ANALYTICAL MODEL}

The moment-curvature relationships of the tested specimens were evaluated analytically using the developed software. The material models for quenched and tempered steel bars, as well as for concrete used in the evaluation are shown in Figure 6. The steel model parameters correspond to the 20-mm bar experimental curves shown in Figure 1b. The parabolic concrete model of Todeschini et al. (1964) was used, and softening in both tension and compression is considered in the analytical model. The theoretical moment-curvature relationship was terminated when concrete crushes at an ultimate compressive strain of 0.0035 . The moment-curvature relationships delivered by the theoretical method are compared with those obtained from the experimental investigation in Figures 7 and 8 for specimens reinforced with tempered rebars and quenched rebars respectively. It can be noticed that there is a good agreement between both theoretical and experimental results in terms of the stiffness, ultimate moment and ultimate curvature.
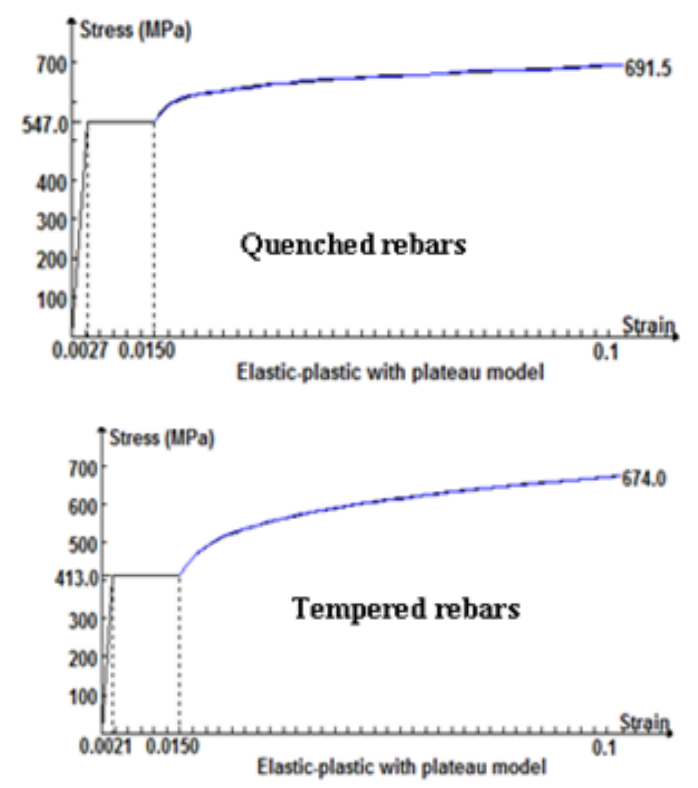


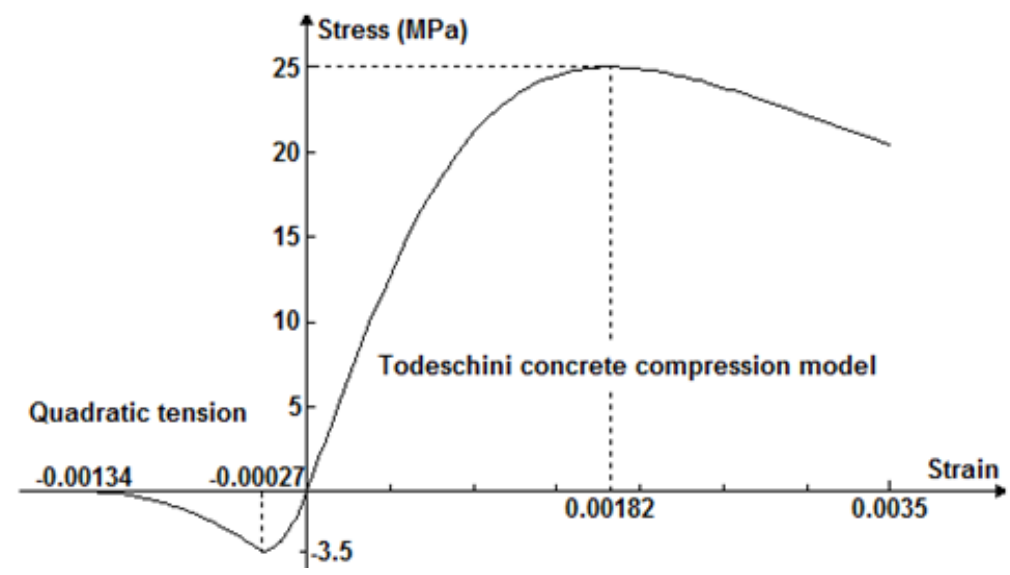

Figure 6: Material models used in the analytical verification.

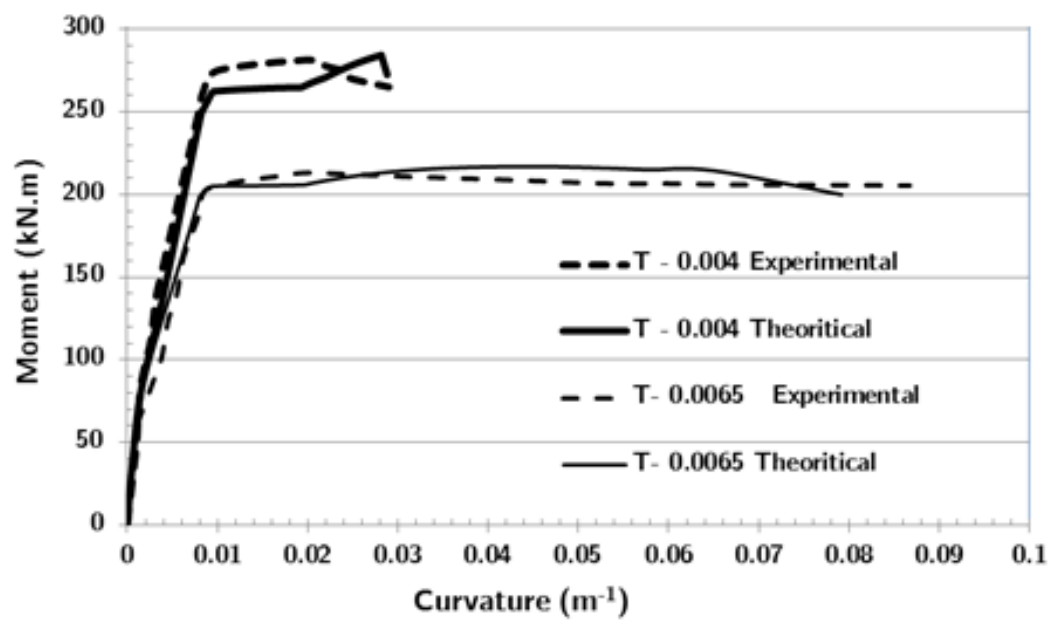

Figure 7: Experimental and theoretical moment-curvature relationships for beams with tempered rebars.

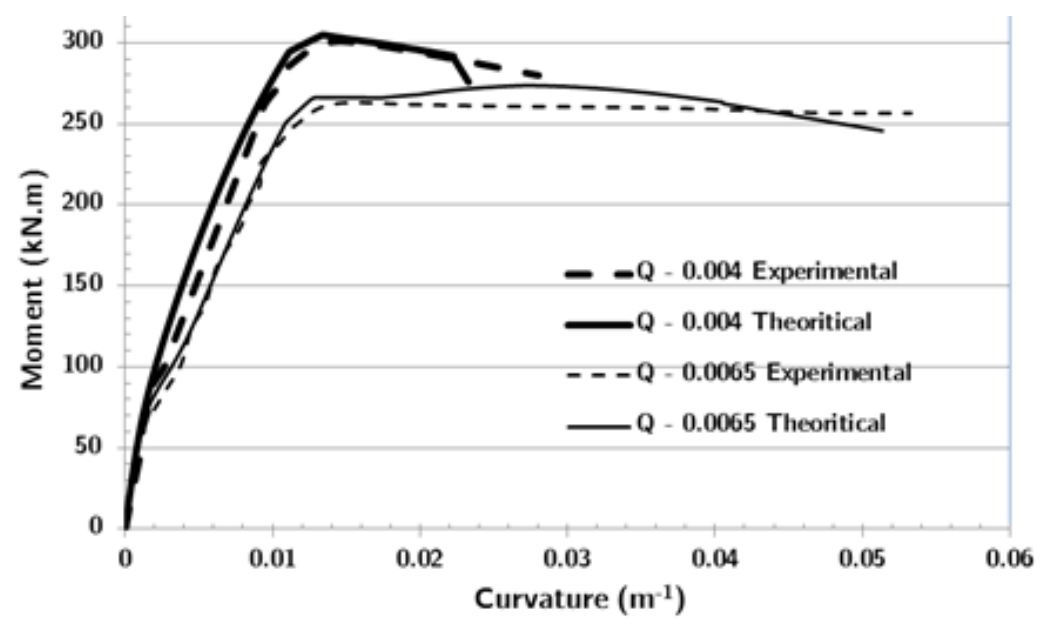

Figure 8: Experimental and theoretical moment-curvature relationships for beams with quenched rebars. 


\section{PARAMETRIC INVESTIGATION}

It was further decided to explore the effects of some important variables on the flexural behavior of beams reinforced with rebars having high yield strength. Among those variables are; section type (drop beam or shallow beam), main tension steel ratio, and steel yield strength. Standard concrete, with 25-MPa compression strength, is again used throughout this investigation with the model shown in Figure 6.

\section{a) Section type}

Two commonly used section types were selected; 260 x $500 \mathrm{~mm}$ drop beam and 500 x $1200 \mathrm{~mm}$ shallow beam. The latter is used for architectural reasons in order to hide beams and constrain their thickness to that of the slab. With a smaller depth, the shallow beams are expected to be more expensive since they need higher amount of steel and larger area of concrete to resist the same ultimate moments that drop beams can resist. The two selected beam sections have the same gross section inertia but the shallow beam contains almost three times more material.

\section{b) Steel ratio}

Assuming a standard yield stress of $420 \mathrm{MPa}$ and an elastic modulus of $200 \mathrm{GPa}$, the corresponding maximum steel ratio for tension control as derived by McGregor et al. (2008) is:

$$
\rho_{\max }=\frac{3}{8} \frac{0.85 \beta_{1} f_{c}^{\prime}}{f_{y}}=0.01613
$$

$\beta_{1}, f_{c}^{\prime}, f_{y}$ are the depth factor of the equivalent rectangular concrete stress block, concrete compression strength, and steel yield stress.

Three different steel ratios " $\rho$ " that cover the practical range in design were used in this investigation. These are: $0.4 \rho_{\max }, 0.6 \rho \max$, and $\rho \max$.

\section{c) Yield stress}

As was noted, the actual steel yield strength is generally greater than its nominal value of 420 MPa for Grade 60, and the excess may reach 60\% (670 MPa) in some cases. The following percentages of increase in yield strength were selected in this investigation; 0\% (control), 15\%, 30\%, 45\% and $60 \%$. The values of ultimate steel strain and end of yielding plateau strain were taken 0.1 and 0.01 respectively.

A typical steel model (control case) used in this investigation is shown in Figure 9. The descending branch recorded in the experimental curves of Figures $1 \mathrm{a}$ and $1 \mathrm{~b}$ is ignored. Table 5 shows the studied values of increase in yield strength, and the corresponding values of yield and ultimate strengths. The studied beam cases are summarized and identified in Table 6 for both the drop and shallow beams.

\begin{tabular}{cccccc}
\hline \hline Increase in Yield & $0 \%$ & 15 & $30 \%$ & $45 \%$ & $60 \%$ \\
strength & & $\%$ & & & \\
Yield stress (MPa) & 420 & 483 & 546 & 609 & 672 \\
Ultimate stress (MPa) & 620 & 660 & 700 & 740 & 780 \\
\hline \hline
\end{tabular}

Table 5: Values of Yield strength and ultimate strength of studied cases. 


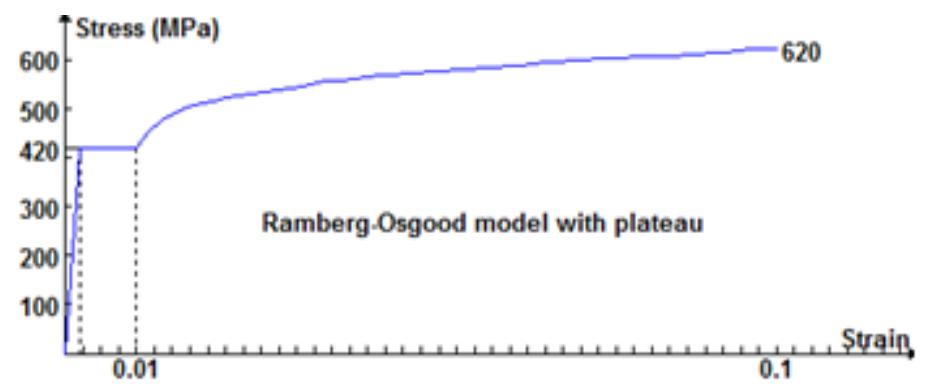

Figure 9: Typical stress-strain curve for steel used in the analytical mode.

\begin{tabular}{|c|c|c|c|c|c|}
\hline \multicolumn{2}{|c|}{ Drop Beams ( 260x500mm) } & \multicolumn{2}{|c|}{$\begin{array}{l}\text { Shallow Beams } \\
(1200 \times 300 \mathrm{~mm})\end{array}$} & \multirow[b]{2}{*}{$\rho / \rho \max$} & \multirow[b]{2}{*}{$\begin{array}{c}\text { Yield } \\
\text { increase }\end{array}$} \\
\hline Code & No of bars & Code & No of bars & & \\
\hline DB- $0.4-0$ & \multirow{5}{*}{$\begin{array}{c}1 \text { layer } \\
3 \Phi 18\end{array}$} & SB- $0.4-0$ & \multirow{5}{*}{$\begin{array}{c}1 \text { layer } \\
6 \Phi 20\end{array}$} & \multirow{5}{*}{0.4} & $0 \%$ \\
\hline DB- $0.4-15$ & & SB- $0.4-15$ & & & $15 \%$ \\
\hline DB- $0.4-30$ & & & & & $30 \%$ \\
\hline DB- $0.4-45$ & & SB- $0.4-45$ & & & $45 \%$ \\
\hline DB- $0.4-60$ & & SB- $0.4-60$ & & & $60 \%$ \\
\hline DB- $0.6-0$ & \multirow{5}{*}{$\begin{array}{c}1 \text { layer } \\
3 \Phi 22\end{array}$} & SB- $0.6-0$ & & & $0 \%$ \\
\hline DB- $0.6-15$ & & SB-0.6- 15 & & \multirow{4}{*}{0.6} & $15 \%$ \\
\hline DB- $0.6-30$ & & SB- $0.6-30$ & 1 layer & & $30 \%$ \\
\hline DB- $0.6-45$ & & SB- $0.6-45$ & $9 \Phi 20$ & & $45 \%$ \\
\hline DB- $0.6-60$ & & SB- $0.6-60$ & & & $60 \%$ \\
\hline DB- $1.0-0$ & \multirow{5}{*}{$\begin{array}{c}2 \text { layers } \\
3 \Phi 20 \\
2 \Phi 20+\Phi 18\end{array}$} & SB- $1.0-0$ & \multirow{5}{*}{$\begin{array}{l}1 \text { layer } \\
12 \Phi 22\end{array}$} & \multirow{5}{*}{1.0} & $0 \%$ \\
\hline DB- $1.0-15$ & & SB- $1.0-15$ & & & $15 \%$ \\
\hline DB- $1.0-30$ & & SB- $1.0-30$ & & & $30 \%$ \\
\hline DB- $1.0-45$ & & SB- $1.0-45$ & & & $45 \%$ \\
\hline DB- $1.0-60$ & & SB- $1.0-60$ & & & $60 \%$ \\
\hline
\end{tabular}

Table 6: Identification of studied beam cases.

\section{RESULTS AND DISCUSSION}

\section{a) Moment-curvature relationships}

The moment-curvature relationships for all studied cases were obtained from the developed software. The curves are given in Figures 10a, 10b, and 10c for drop beams with steel ratios $\left(\rho / \rho_{\max }\right)$ equal 0.4, 0.6 and 1.0 respectively. The corresponding curves for shallow beams are given in Figures $11 \mathrm{a}, 11 \mathrm{~b}$, and 11c. 
As can be noted, the ultimate beam curvature decreases and the ultimate moment increases when the steel ratio or/and the steel yield strength increase. Shallow beams experienced higher ultimate moments and ultimate curvatures as compared to those of drop beams because of their larger section. Such reductions in beams ultimate curvatures due to the increase in the steel yield strength can result in negative impact as far as ductility is concerned.

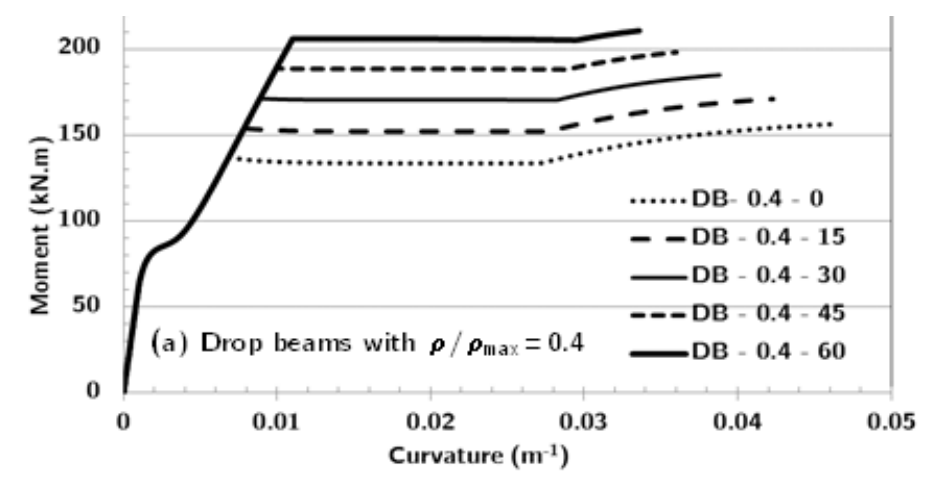

Figure 10a: Moment-curvature of studied drop beams $\left(\rho / \rho_{\max }=0.4\right)$.

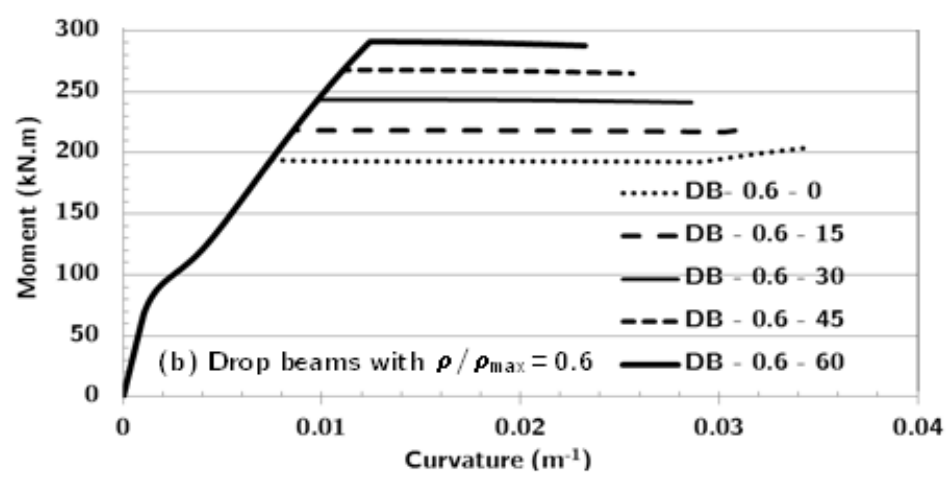

Figure 10b: Moment-curvature of studied drop beams $(\rho / \rho \max =0.6)$.

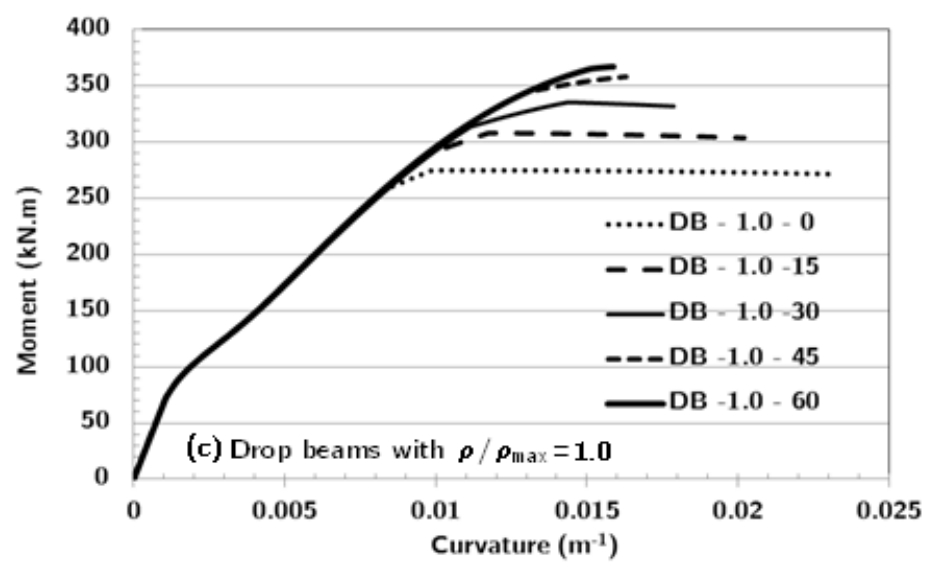

Figure 10c: Moment-curvature of studied drop beams $\left(\rho / \rho_{\max }=1.0\right)$. 


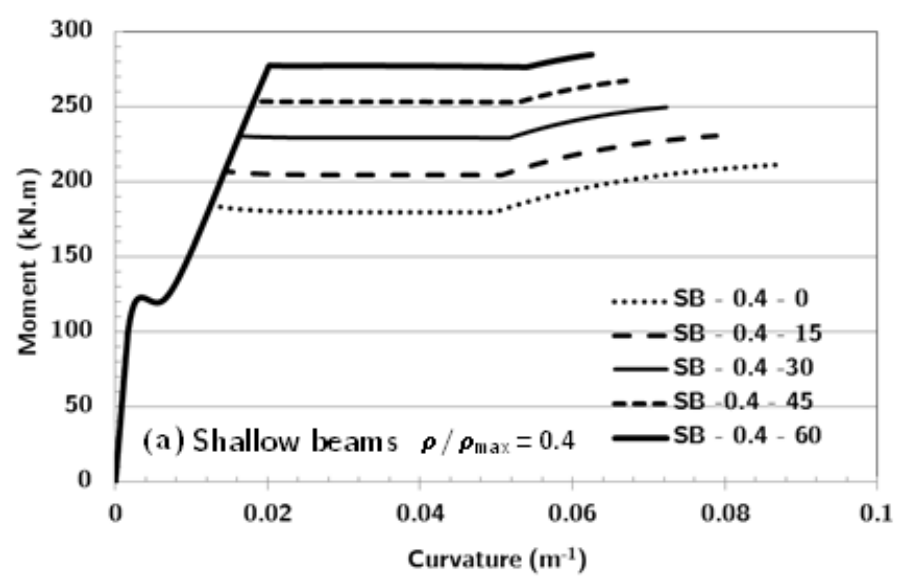

Figure 11a: Moment-curvature of studied shallow beams $\left(\rho / \rho_{\max }=0.4\right)$.

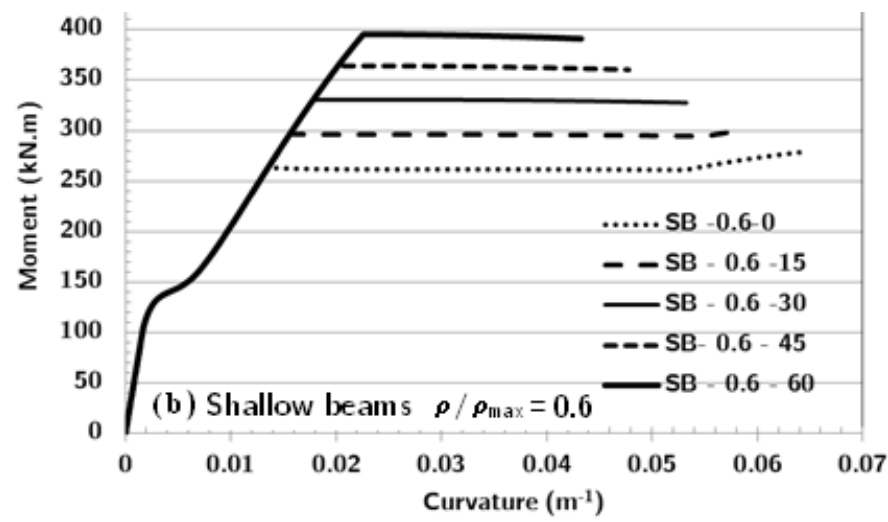

Figure 11b: Moment-curvature of studied shallow beams $(\rho / \rho \max =0.6)$.

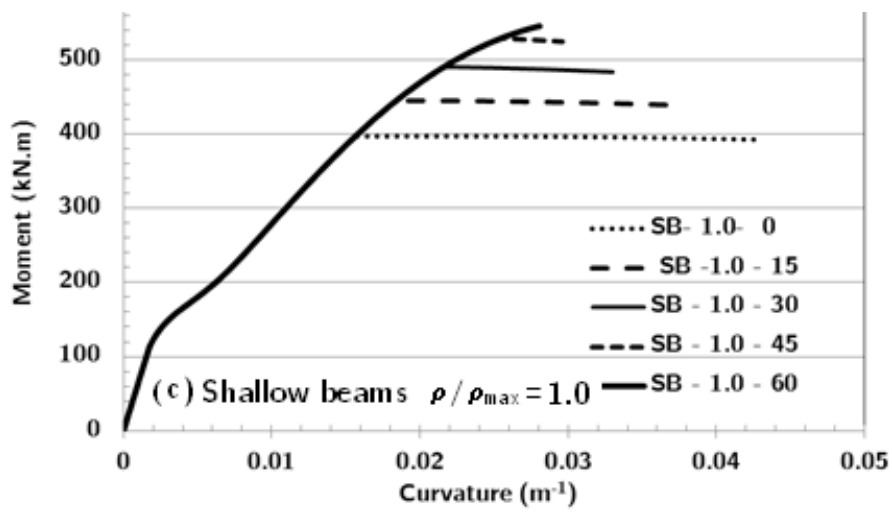

Figure 11c: Moment-curvature of studied shallow beams $\left(\rho / \rho_{\max }=1.0\right)$.

\section{b) Steel strain and ductility}

The effect of the increase in steel yield strength on the recorded ultimate steel strain is shown in Figure 12, for different steel ratios and beam sections. It can be observed that the increase in steel 
yield strength reduces the ultimate steel strains especially for larger steel ratios. Both beam sections exhibit the same behavior with almost the same values of ultimate steel strains. Although the beam sections were designed as tension controlled members with a strain greater than 0.005 , the ultimate steel strains can go below the 0.005 limit of tension failure control. Such violation cases occur when the steel ratio is equal to $\rho_{\max }$ and the increase in yield stress exceeds $20 \%$. Such concerning behavior is observed for both drop beam and shallow beam sections.

The curvature ductility of beam sections was computed by dividing the ultimate curvature by the first yield curvature. The effect of the increase in steel yield strength on the curvature ductility is shown in Figure 13, for different steel ratios and beam sections. The reduction of curvature ductility is obvious with the increase in steel yield strength and the steel ratio for both beam sections. In fact shallow beam case (SB-1.0- 60) with max steel ratio and increase of $60 \%$ in steel yield strength becomes compression controlled as steel does not reach the yield value, as can be noticed in Figure 13, resulting in zero ductility.

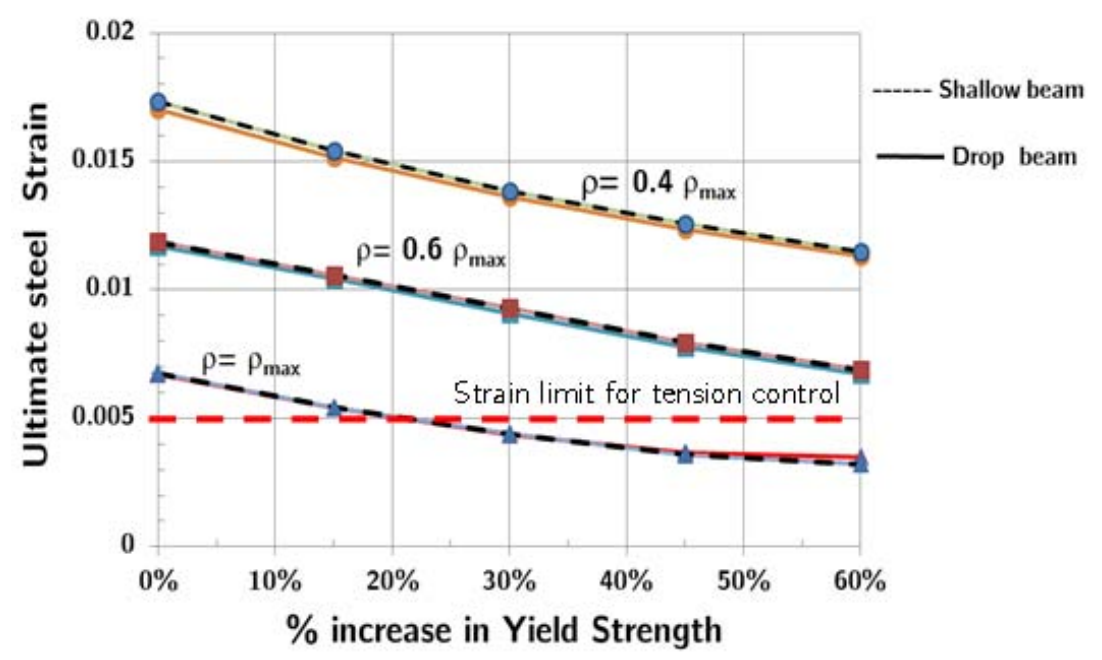

Figure 12: Variation of ultimate steel strains with the increase in steel yield strength.

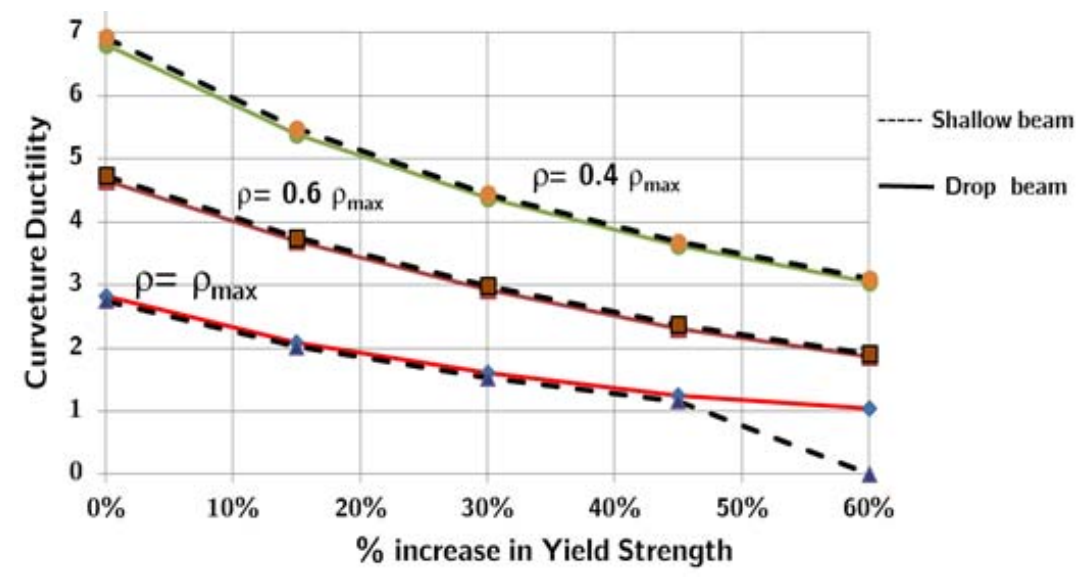

Figure 13: Variation of curvature ductility with the increase in steel yield strength. 


\section{PROPOSED SOLUTION}

The increase in steel yield strength has a negative impact by reducing the beam ductility and a positive effect by increasing the beam's moment capacity. However in seismic design it is required to provide sufficient ductility without reducing the ultimate moment capacity. To achieve such a goal with an unexpected increase in steel yield strength, a new procedure for computing the maximum tension steel ratio, above which compression reinforcement is required, is proposed.

The modified maximum steel ratio is derived from the standard expression (5) and takes into account the yield strength increase through the ratio of actual to nominal value of yield strength " $\gamma_{y}$ ". The newly proposed expression is :

$$
\left(\rho_{\text {max }}\right)_{\text {modified }}=\frac{3}{8} \frac{0.85 \beta_{1} f_{c}^{\prime}}{\gamma_{y} f_{y}}
$$

Such an equation will reduce the $\rho_{\max }$ by the factor $\left(1 / \gamma_{\mathrm{y}}\right)$, and allows the beam to exhibit tension control failure and avoid reduction in ductility. However, this will reduce the maximum moment capacity when using tension steel only. In order to increase the beam's ultimate moment capacity without exceeding the modified maximum steel ratio, compression steel must be added.

Such a proposed solution is demonstrated for the case DB-1.0-60 where $\rho_{\max }$ is equal to 0.01613 $(5 \phi 20+1 \phi 18)$ and $60 \%$ increase in yield strength. The ultimate moment and ductility are 367.145 kN.m, and 1.0483 respectively. The corresponding modified maximum steel ratio will be 0.01613/1.6 $=0.0101(3 \phi 22)$ with steel yield strength equal to $420 \times 1.6=672 \mathrm{MPa}$. This case is denoted as DB-0.6-60. The resulting moment-curvature relationship is compared with that of DB-1.0-60 in Figure 14. The enhanced ductility reached 1.8688 but with a lower ultimate moment capacity of $291.08 \mathrm{kN}$.m. The second modification is to increase its ultimate moment capacity to reach that of DB-1.0-60 (367.145 kN.m) by adding compression steel of $2 \phi 18$, and the same amount at tension side so that the total tension steel will be $5 \phi 20$, this case is denoted as DB-M2-60. The resulting moment-curvature relationship is compared with those of previous cases in Figure 14. Both enhanced ductility and moment capacity are achieved even by using steel with $60 \%$ increase in yield strength. However, the increase in amount of reinforcements needed for such a modification for DBM2-60 reaches about 14\% increase as compared to DB-1.0-60.

The same previous procedure was applied to modify the reinforcement of shallow beam SB-M260 with an increase of $60 \%$ in steel yield strength, in order to achieve the same ultimate moment of $545.74 \mathrm{kN} . \mathrm{m}$ as beam SB-1.0-60 (12Ф22 bottom steel) and the same ductility of 1.9142 as beam SB0.6-60 (9Ф22 bottom steel). The modified beam reinforcement for SB-M2-60 was found to be $11 \Phi 22$ bars in tension and 10Ф20 bars in compression. The moment-curvature relationship for SB-M2-60 is compared with those of beams SB-1.0-60 and SB-0.6-60 in Figure 15. SB-M2-60 beam achieves the same strength as SB-1.0-60 but it does not reach the same ductility as beam SB-0.6-60, since it needs more compression reinforcement. Compared to drop beams, shallow beams required more compression steel to perform the modification. It is worth mentioning that the increase in reinforcement needed for SB-M2-60 was about $60 \%$ of that for SB-1.0-60, confirming again that shallow beams are inappropriate an more expensive than drop beams; and thus should only be used in exceptional cases. 


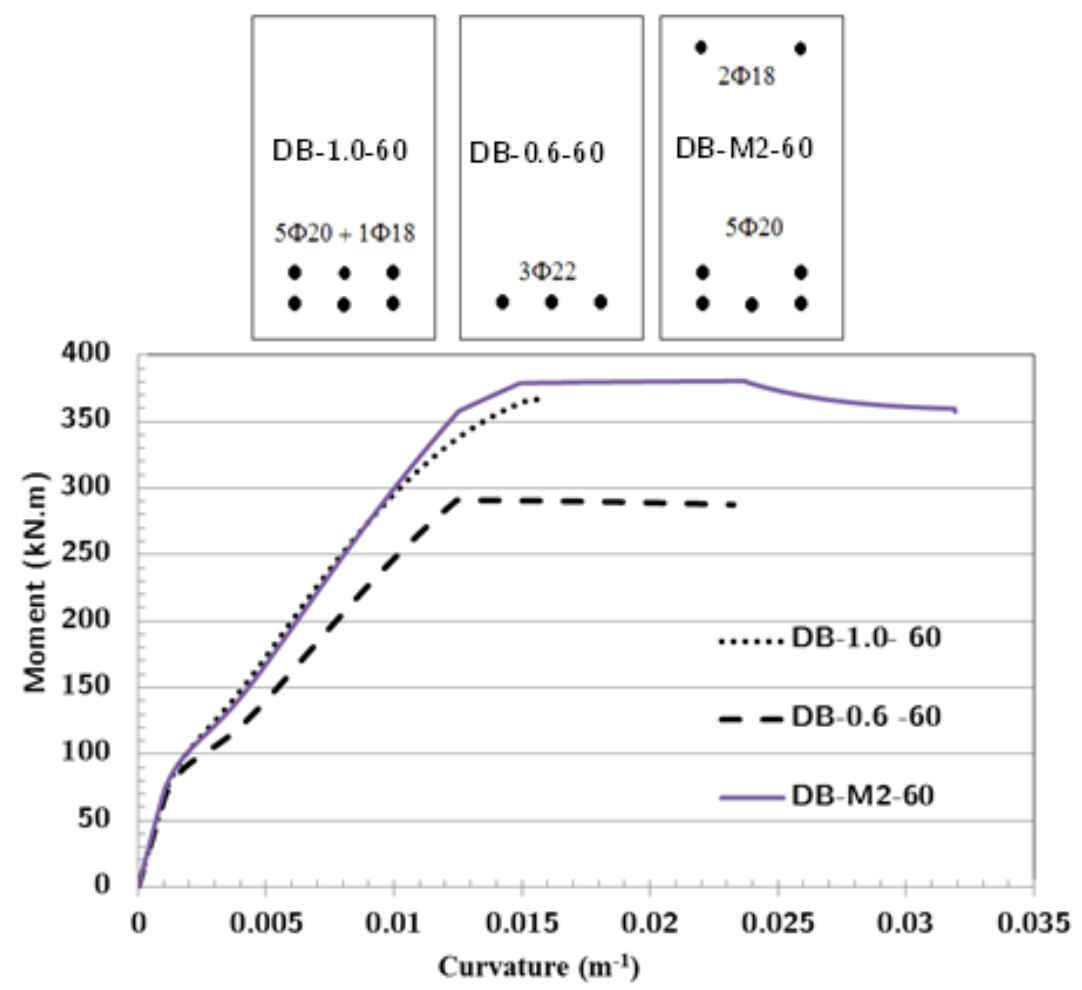

Figure 14: Moment-curvature relation of the proposed drop beam DB-M2-60.

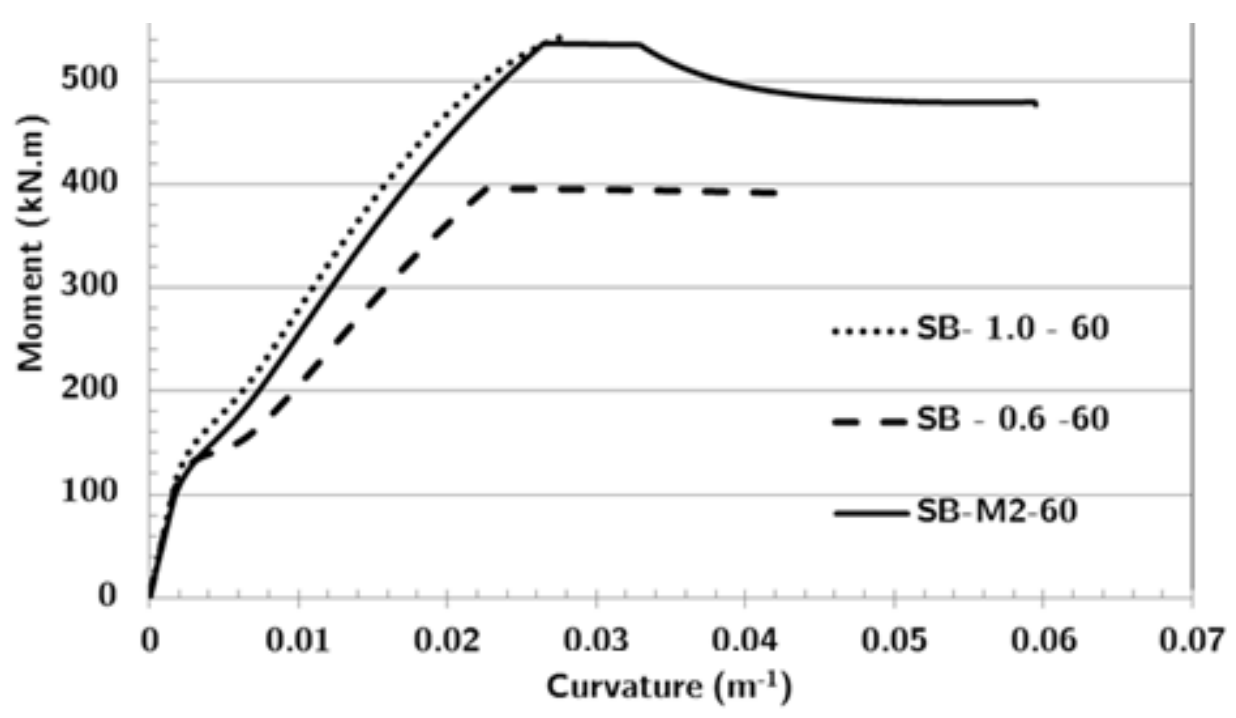

Figure 15: Moment-curvature relation of the proposed drop beam SB-M2-60.

\section{CONCLUSIONS}

Standard quality control for reinforced concrete structures usually aims at avoiding strength reduction in both concrete and steel materials, considering any strength increase as positive and favora- 
ble. While for concrete any strength increase may effectively be welcome without concern, for steel however an unexpected increase in yield strength may reduce the structural ductility and violate the tension-control condition of reinforced concrete beams. This violation would be even more dangerous if combined with an unexpected reduction in concrete strength. The higher than nominal yield values of some steel rebars produced by some manufacturers can no longer be considered favorable.

From the experimental tensile tests on rebars manufactured by both tempering and quenching processes, it was shown that the ratios of mean to nominal values for yield strength " $\gamma_{\mathrm{y}}$ " are higher for rebars manufactured by quenching process, and can reach values up to 1.40. The effect for such high yield strengths was investigated experimentally on full-scale beams. Results showed the negative effect in terms of ductility reduction. It was also shown that specimens made of quenched rebars exhibit higher ultimate moments with less curvature and ductility as compared to those specimens made of tempered steel. Such behavior was expected since rebars having higher yield strength will not be able to experience the whole yielding plateau before concrete failure. The analytical integration method of stress resultants described in this work is very efficient. It deals with any complex shaped section and can be performed on any polynomial model and other specific models. The method was used to compare moment-curvature with experimental results and the comparison was very good. The effects of both high yield value and reinforcement ratio observed in the experimental part are confirmed by the analytical study. Some important variables affecting the flexural behavior of beams reinforced with rebars having high yield strength, were investigated. The effect of section type and level of yield strength on the beam curvature and the ultimate steel strain were explored. The ultimate beam curvature decreases and the ultimate moment increases by increasing the steel ratio and the steel yield strength. In addition, the increase in steel yield strength reduces the ultimate steel strains especially for higher steel ratios. Both drop and shallow beam sections exhibit the same behavior with almost the same values of ultimate steel strains. Although the beam sections were designed as tension controlled members with a strain greater than 0.005 , the ultimate steel strains can be reduced below this limit. Such violation cases occur when the steel ratio is equal to pmax and the increase in yield stress exceeds $20 \%$. Such an undesirable behavior is observed for both drop beam and shallow beam sections. These negatives effect on ductility can be avoided by reducing the maximum allowed tension steel ratio by a suggested factor " $1 / \gamma_{\mathrm{y}}$ ".

\section{Acknowledgment}

The authors would like to acknowledge the financial support and express their gratitude to the Deanship of Scientific Research at King Saud University for funding the work through the research group project No. RGP-VPP-105.

\section{References}

ACI Committee 318 (2011), "Building code requirements for structural concrete (ACI 318-2011), American Concrete Institute, Farmington Hill, Michigan.

Al-Haddad, M. (1995), "Curvature ductility of R.C beams under low and high strain rates" ACI Structural Journal, Vol. 92, No. 5, pp. 526-534.

Al-Haddad, M. (2006), "Permissible maximum ratio of Saudi reinforcing bars for design of RC beams" Final research report No 24/424, King Saud University, 29p. 
Allorani, M., et al. (2012), "Tensile Strain limits for ductile design of RC beams reinforced with Saudi rebars" Senior Undergraduate Project CE 499-32/33-I-02/2, Department of Civil Eng., King Saud University.

Batista J., Sousa M. Jr., Muniz C. (2007), "Analytical integration of cross-section properties for numerical analysis of reinforced concrete, steel and composite frames", Engineering Structures, (29),618-625

Bonet J.L., Barros M.H.M., Romero M.L. (2006), "Comparative study of analytical and numerical algorithms for designing reinforced concrete sections under biaxial bending", Computers and Structures, Vol.84, pp.2184-2193

Charalampakis A.E., Koumousis V.K. (2008), "Ultimate strength analysis of composite sections under biaxial bending and axial load", Advances in Engineering Software 39, 923-936

Charif A., Shannag J., Dghaither S. (2014), "Ductility of reinforced lightweight concrete beams and columns", Latin American Journal of Solids and Structures, Vol.7 No 11, pp.1251-1274

Davis, H. E., et al. (1982), "The Testing of Engineering Materials," McGraw-Hill, $4^{\text {th }}$ ed.

Fafitis A. (2001), "Interaction surfaces of RC sections in biaxial bending", Jnl Struct Eng, ASCE, 127(7):840-6.

MacGregor J.G., White J.K. (2008), "Reinforced Concrete: Mechanics and Design", 5 th edition, by, Prentice-Hall.

Milbourn, D. (2010), "Metallurgical Benefits of Vanadium Microalloying in Producing High Strength Seismic Grade Rebar", Proceedings of International Seminar on Production and Application of High Strength Seismic Grade Rebar Containing Vanadium Beijing China.

Sfakianakis M.G. (1999), "Biaxial bending with axial force of reinforced, composite and repaired concrete sections of arbitrary shape by fiber model and computer graphics", Journal of Structural Engineering,125(6):672-83.

Si Youcef, Y., Chemrouk M. (2012), "Curvature Ductility Factor of Rectangular Sections Reinforced Concrete Beams", World Academy of Science, Engineering and Technology, Vol.6, pp.11-20

Todeschini C.E., Bianchini A.C., Kesler C.E. (1964), "Behavior of concrete columns reinforced with high strength steels," ACI Journal Proceedings, Vol. 61, No. 6, pp. 701-716.

Zhou K.J.H., Ho J.C.M., Su R.K.L., "Flexural Strength and Deformability Design of Reinforced Concrete Beams", The Twelfth East Asia-Pacific Conference on Structural Engineering and Construction, Procedia Engineering 14 (2011) 1399-1407

Zupan D., Saje M. (2005), "Analytical integration of stress field and tangent material moduli over concrete crosssections", Computers and Structures, No.85, pp.2368-80 